\title{
ASPECTOS CARDIOVASCULARES DA INIBIÇÃO DA COX-2 EM ANIMAIS COM PERIODONTITE
}

Reila Tainá MENDES, Daniel Augusto Bueno MENDES, Renato SOUSA, Fábio André DOS SANTOS, Daniel FERNANDES

A inflamação sistêmica gerada pela periodontite se relaciona a disfunção endotelial e a eventos cardiovasculares. A enzima COX-2 está envolvida no desenvolvimento da disfunção endotelial. A proposta deste trabalho é avaliar os efeitos cardiovasculares da inibição da COX-2 em animais com periodontite induzida por ligadura, e em animais com periodontite e infartados. No dia 0 , ratos Wistar foram divididos em 4 grupos de 6 animais: G1: ligaduras nos primeiros molares inferiores e segundos molares superiores + Etoricoxibe(10 $\mathrm{mg} / \mathrm{kg} / \mathrm{dia}$, v.o.); G2: falso-operados, as ligaduras foram colocadas e imediatamente retiradas + Etoricoxibe; G3: ligadura+veículo; G4: falsooperados+veiculo. $O$ tratamento com etoricoxibe ou veículo se deu do dia 14 ao dia 20. No dia 21, fez-se análise da pressão arterial, frequência cardíaca e reposta pressórica à fenilefrina, angiotensina II e isoprenalina. Em outro lote de experimentos os grupos acima foram infartados com isoprenalina $(80 \mathrm{mg} / \mathrm{kg}$, s.c.) nos dias 20 e 21 . No dia 22 , os corações foram removidos para análise histológica. $O$ etoricoxibe reduziu a freqüência cardíaca do grupo ligadura $(p<0,05)$. Histologicamente observou-se maior infiltrado inflamatório cardíaco no grupo etoricoxibe $(p>0,05)$. Sugere-se que a inibição da COX-2 em animais com inflamação gera alterações vasculares e histológicas.

Palavras-chave: Periodontite; Coração; Disfunção endotelial. 